\title{
A STUDY OF ASSOCIATED RISK FACTORS OF URINARY TRACT INFECTION AMONG PREGNANT WOMEN AT KAMLA RAJA HOSPITAL, GWALIOR
}

\begin{tabular}{ll}
\hline Gynaecology & \\
$\begin{array}{l}\text { Dr. Achala sahai } \\
\text { Sharma }\end{array}$ & Associate professor, department of obstetrics and gynaecology, GRMC, Gwalior \\
\hline Dr Udit Mishra & Associate professor, department of urology, GRMC, Gwalior \\
\hline $\begin{array}{l}\text { Dr Rajkishori } \\
\text { Dandotiya }\end{array}$ & Assistant professor, department of obstetrics and gynaecology, GRMC, Gwalior \\
\hline $\begin{array}{l}\text { Dr Paribhashita } \\
\text { Mishra* }\end{array}$ & $\begin{array}{l}\text { Associate professor, department of obstetrics and gynaecology, GRMC, Gwalior } \\
\text { *Corresponding Author }\end{array}$ \\
\hline
\end{tabular}

\section{ABSTRACT}

Background Urinary tract infection (UTI) is an infection caused by presence and growth of microorganism anywhere in the urinary tract. Urinary tract infection in pregnancy may also lead to unfavorable pregnancy outcomes and complication such as pyelonephritis, hypertensive disease of pregnancy, anaemia, chronic renal failure, premature delivery, low birth weight and foetal mortality. Aims and objectives: To determine the overall prevalence of UTI among pregnant women and to identify bacterial uropathogen associated with UTI in pregnant women and determine their antibiotic susceptibility to select antimicrobial agents. Materials and methods: It is a cross sectional study conducted in the department of obstetrics and Gynaecology, Kamla Raja Hospital, Gwalior (MP), for one year (February 2016-January 2017) on 300 pregnant patients with symptoms of UTI. Result and observations: Our study showed that pregnant women in their second trimester were more infected $(80 \%)$ than those in comparisons to first trimester $(7.5 \%)$ and 3rd trimester $(12.5 \%)$ respectively which was statistically significant (p 0.05). Prevalence of UTI is higher in pregnant women with hemoglobin level $(<10 \mathrm{gm} \%)$ as compare to pregnant women with hemoglobin $(>10 \mathrm{gm} \%)$ which was statistically significant $(\mathrm{p}<0.05)$. The most common pathogen isolated is E.coli. Conclusion: Antenatal women and their families should be made aware about the need for early diagnosis and efficient treatment of UTI during pregnancy. Good personal hygiene and nutrition of all antenatal women should be ensured. Need of strict aseptic and antiseptic precaution for urethral catheterization and effective management of recurrent UTI should be reinforced among health personnel.

\section{KEYWORDS}

\section{UTI, Bacteriuria.}

\section{INTRODUCTION}

Urinary tract infection (UTI) is an infection caused by presence and growth of microorganism anywhere in the urinary tract. It is due to bacteria from the genital tract which climb the opening of the urethra and begin to multiply to cause infection. In contrast to men, women are more susceptible to UTI, and this mainly due to short urethra, pregnancy and easy contamination of the urinary tract with fecal flora. Urinary tract infection in pregnancy may also lead to unfavorable pregnancy outcomes and complication such as pyelonephritis, hypertensive disease of pregnancy, anaemia, chronic renal failure, premature delivery, low birth weight and foetal mortality. The incidence of these complications can be decreased by treating promptly of symptomatic and asymptomatic bacteruia during pregnancy. Due to the potential adverse sequel of UTI in pregnancy, most clinics perform routine urinalysis of midstream specimen during one or more antenatal clinic (ANC) visit. However, culture and sensitivity testing are needed for surveillance purposes to guide the clinicians on the proper management and empirical treatment of pregnant women with asymptomatic and symptomatic bacteruria.

UTI can be symptomatic or asymptomatic. Asymptomatic bacteuria $(A B U)$ is a condition which is characterized by presence of bacteria in clear-voided midstream urine specimen that yields positive culture $\left(\geq 10^{5} \mathrm{cfu} / \mathrm{ml}\right)$ of the same uropathogen, in a patient without classical symptoms of UTI, whereas patients with significant bacteruia who have symptoms referable to the urinary tract are said to be symptomatic bacteriuria.

UTIs that occur in a normal genitourinary tract with no prior instrumentation are considered as "uncomplicated, "whereas complicated" infections are diagnosed in genitourinary tracts that have structure or functional abnormalities, including instrumentation such as indwelling urethral catheters. However, as with many community acquired infections, antimicrobial resistance among pathogens that cause UTIs is increasing and is a major health problem in the treatment of UTI. There is growing concern regarding antimicrobial resistance worldwide, particularly to E.coli which is the dominant causative agent of UTI in pregnant women.

In most developing countries including India, screening for UTIs in pregnancy is not considered as an essential part of antenatal care. Therefore, the present study was designed to determine the bacterial profile and antimicrobial susceptibility pattern of uropathogen among pregnant women in Kamla Raja Hospital, Gwalior (M.P.) that will give an area based prevalence and antibiotic sensitivity pattern for empirical treatment.

\section{AIMS AND OBJECTIVES}

General objectives: To determine and analyze the risk factors associated with UTI in pregnant women attending antenatal clinic at $\mathrm{KRH}$.

Specific objectives: To determine the overall prevalence and to identify bacterial uropathogen associated with UTI in pregnant women and determine their antibiotic susceptibility to select antimicrobial agents.

MATERIAL AND METHODS: Present study is cross sectional study conducted in the department of obstetrics and Gynaecology, Kamla Raja Hospital, Gwalior (MP), for one year (February 2016January 2017) on 300 pregnant women with symptoms of UTI.

EXCLUSION CRITERIA: known case of diabetes, History of renal transplantation, immunosuppression, drug intake, renal disease, history of being treated with antibiotic agent for more than 2 weeks prior to the day of specimen collection.

\section{METHODS:}

Total 300 pregnant women irrespective of age, parity, gestational age were selected to ascertain the frequency and pattern of urinary symptoms as well as the risk factors of UTI such as age, parity, education level, past history of UTI, Hemoglobin level, past history of catheterization, past history of contraception among women attending antenatal clinic at Kamla Raja hospital, Gwalior (MP)

Data collection: Informed consent was taken and data collected on a self-design performa. A pretest semi structured questionnaire was used to obtain socioeconomic data from pregnant women. Some demographic data- age, education, occupation, residence address, income and housing condition. Past obstetric history - parity and living 
children. Present obstetric history-gestational age, symptoms of any troubles. Personal hygiene, "on the basis of good hygiene and poor hygiene. Past history of urinary tract infections and contraceptive usage if any. Past history of catheterization and $\mathrm{Hb}$ level. All the selected women advised for complete examination of urine. Clean catch mid-stream urine samples were collected using sterile, wide mouth bottle with rubber cap.

Urine analysis: Urine analysis was transported immediately to the clinical pathology lab. With a calibrated wire loop, urine was streaked on blood agar and MacConkey agar incubated at 37c for 24 hours. Different tests on urine performed including, biochemical analysis, microscopy "considering growth is significant if $10^{5} \mathrm{cfu} / \mathrm{ml}$ bacteria is present and finally antibiotic sensitivity. Urine routine microscopy is positive if there is presence of more than 10 pus cells per high power field (40X). UTI is positive if there is $10^{5} \mathrm{cfu} / \mathrm{ml}$ of a single pathogen. One bacterium per oil immersion field on gram stain indicated a positive culture.

\section{DATAANALYSIS:}

Data obtained was analyzed statistically using Chi square test to determine the relationship between variables and its significance. Differences were considered significant at p-value 0.05 .

\section{RESULT:}

Our study showed that pregnant women in their second trimester were more infected $(80 \%)$ than those in comparisons to first trimester $(7.5 \%)$ and $3^{\text {rd }}$ trimester $(12.5 \%)$ respectively which was statistically significant ( $\mathrm{p} 0.05$ ).UTI reported in sexually active pregnant women are high $(81 \%)$ in comparison to sexually inactive pregnant women during pregnancy $(19 \%)$ which shows significant association with UTI $(p<0.05)$. Women with poor personal hygiene have higher percentage $(54 \%)$ in compared to women with good personal hygiene $(46 \%)$ and significantly associated with positive culture and presence of UTI $(\mathrm{p}<0.05)$. Our study showed that low socioeconomic status was one of the factors that were highly associated with increased UTI. High prevalence of UTI was found in women belonging to lower socioeconomic status $(56.2 \%)$ in comparison to higher socioeconomic status $(12.5 \%)$. Prevalence of UTI is higher in pregnant women with hemoglobin level $(<10 \mathrm{gm} \%)$ as compare to pregnant women with hemoglobin $(>10 \mathrm{gm} \%)$ which was statistically significant $(\mathrm{p}<0.05)$.

Table: 1. Distribution Of Cases According To Past History Of Uti

\begin{tabular}{|c|c|c|c|c|c|c|c|c|}
\hline $\begin{array}{c}\text { Past history of } \\
\text { UTI }\end{array}$ & \multicolumn{2}{|c|}{$\begin{array}{c}\text { Total urine } \\
\text { sample }\end{array}$} & \multicolumn{4}{|c|}{ Culture report } & p-value & \multirow{3}{*}{} \\
\hline & No. & $\%$ & Negative & Positive & & \\
& & & No & $\%$ & No. & $\%$ & \multirow{3}{*}{0.013} & 6.07 \\
\hline & 195 & 65 & 134 & 61 & 61 & 77 & & \\
\hline YES & 105 & 35 & 86 & 39 & 19 & 23 & & \\
\hline NO & 300 & 100 & 220 & 100 & 80 & 100 & & \\
\hline Total & 30 &
\end{tabular}

Table: 2. Distribution Of Cases According To Past History Of Catheterization

\begin{tabular}{|c|c|c|c|c|c|c|c|c|}
\hline \multirow{3}{*}{$\begin{array}{l}\text { Past history of } \\
\text { catheterization }\end{array}$} & \multirow{2}{*}{\multicolumn{2}{|c|}{$\begin{array}{l}\text { Total } \\
\text { sample }\end{array}$}} & \multicolumn{4}{|c|}{ Culture report } & \multirow[t]{3}{*}{ P value } & \\
\hline & & & \multicolumn{2}{|c|}{ Negative } & \multicolumn{2}{|c|}{ Positive } & & \\
\hline & No & $\%$ & & $\%$ & No & $\%$ & & \\
\hline Yes & 65 & 22 & 10 & 5 & 55 & 69 & 0.001 & 142.49 \\
\hline No & 325 & 78 & 210 & 95 & 25 & 31 & & \\
\hline Total & 300 & 100 & 220 & 100 & 80 & 100 & & \\
\hline
\end{tabular}

Prevalence of UTI is higher in pregnant women with hemoglobin level $(<10 \mathrm{gm} \%)$ as compare to pregnant women with hemoglobin $(>10 \mathrm{gm}$ $\%)$ which was statistically significant $(\mathrm{p}<0.05)$.

Table:3. Distribution Of Cases According To Bacterial Isolation

\begin{tabular}{|l|l|}
\hline Isolated bacteria & No of bacteria isolated $\{\mathrm{n}=80\}$ \\
\hline E.coli & $32[40]$ \\
\hline S.aureus & $16[20]$ \\
\hline P.aerugenosa & $9[10.25]$ \\
\hline P.mirabilis & $22[25]$ \\
\hline Enterobacter & $11[13.75]$ \\
\hline C.sakajaki & $2[2.5]$ \\
\hline C.fruanci & $2[2.5]$ \\
\hline K.pneumniae & $6[7.5]$ \\
\hline &
\end{tabular}

DISCUSSION:

In our study most predominant isolated organism was E.coli (40\%) followed by S.aureus (20\%) as found in many other studies like study done by IA Onwuezobe et al (2015). Age, educational status and use of contraception were the risk factors not significantly associated with UTI. In our study, prevalence of UTI was high among women who belong to $2^{\text {nd }}$ trimester $(80 \%)$ in comparison to first $(7.5 \%)$ and third $(12.5 \%)$ trimester respectively. The results were similar to study done by Emiru et al (2013). They also found highest prevalence of UTI in $2^{\text {nd }}$ trimester of pregnancy $(79 \%)$.

Our study showed that low socioeconomic status was one of the factors that were highly associated with increased UTI. High prevalence of UTI was found in women belonging to lower socioeconomic status $(56.2 \%)$ in comparison to higher socioeconomic status $(12.5 \%)$.This could be due to relation of low socioeconomic status with nutrition and immunity specially in pregnant women. This observation correlated with findings of similar study done by Manjula et al (2013).

Maternal anemia was found to be significantly associated with UTI. In our study, prevalence of UTI was more in women who have lower level of Hemoglobin (83\%) in comparison to those women who have high Hemoglobin level (17\%).Similar result were obtained by Rutuja et al (2015)

Sexual activity was also the other risk factor that was found to be significantly associated with UTI. This may be due to the fact that it increases the chances of bacterial contamination of female urethra. In this study, UTI reported in sexually active women are high $81 \%$ in comparison to sexually inactive women during pregnancy. The group with no sexual activity during pregnancy have less incidence of UTI(19\%). The findings is in agreement with previous study by Haider et al (2010).

Multiparity was associated with significant bacteuria in pregnancy. This association between multiparity and UTI is due to profound physiological changes affecting the entire urinary tract during repeated pregnancy. In our study, higher percentage of UTI $73 \%$ was seen in parity group 2-3 and lowest $12 \%$ in parity group $0-1$

The difference in the results about the presence and absence of association between associated risk factors and UTI among different studies may be due difference in methodologies, study population and sample size used in studies

\section{SUMMARY:}

The highest incidence was found in the age group of $30-35$ years $(56 \%)$ and incidence was lowest in the age group of $20-30$ years $(12 \%)$.The UTI was found to more prevalent in pregnant women in their $2^{\text {nd }}$ trimester $(80 \%)$ than in comparison to $3^{\text {rd }}$ Trimester $(12.5 \%)$ and first trimester (7.5\%). Highest incidence of UTI (73\%) was seen in parity group 2-3 and lowest in parity group $0-1$ which was significantly associated with UTI ( $p$ 0.05). UTI reported in sexually active pregnant women are high $(81 \%)$ in comparison to sexually inactive pregnant women during pregnancy $(19 \%)$ which shows significant association with UTI. Past history of UTI in pregnant women is also significantly associated with UTI in comparison to those who did not have history of UTI. Prevalence of UTI is high among women with previous history of UTI (77\%) than women who did not have any history of UTI in past (23\%). Previous use of contraception shows high prevalence rate $91 \%$ and lowest prevalence rate in $9 \%$ in those women who do not have history of contraception use, but was not found to be statistically significant. Prevalence of UTI was high in pregnant women with poor personal hygiene (54\%) in comparison to women with poor personal hygiene $(46 \%)$. Higher incidence $(69 \%)$ of bacterial isolation and UTI are reported in pregnant women with history of catheterization in compared to those without past history of catheterization $(31 \%)$. Prevalence of UTI in pregnant women with haemoglobin level (10gm \%) $83 \%$ was significantly higher than those haemoglobin level was $10 \mathrm{gm} \%(17 \%)$. Pregnant women who belongs to monthly income Rs. $5000(56.2 \%)$ had high incidence of UTI than those belongs to monthly income group Rs. 5000-10000; Rs 10000-20000; and 20000 where in incidence was $10 \%, 21.3 \%$ and $12.5 \%$ respectively.

\section{CONCLUSION:}

Given the fact that UTI has higher prevalence in pregnant women and may lead to many grave problems, emphasis have to give on the need of regular antenatal care where in every pregnant women should be meticulously evaluated to rule out UTI. Antenatal women and their 
families should be made aware about the need for early diagnosis and efficient treatment of UTI during pregnancy. Good personal hygiene and nutrition of all antenatal women should be ensured. Need of strict aseptic and antiseptic precaution for urethral catheterization and effective management of recurrent UTI should be reinforced among health personnel. Routine urine culture in pregnant women may help in early and accurate diagnosis and to prevent adverse outcome. Last, but not the least education $\mathrm{fgeneral} \mathrm{population} \mathrm{about} \mathrm{all} \mathrm{the} \mathrm{associated} \mathrm{risk}$ factor of UTI in pregnant women and their prevention will go a long way in curbing the problem.

\section{REFERENCES}

1. Delzell JE. Urinary tract infections in pregnancy. Am. Acad. Fam. Phys.pg. 2000: 721

2. Rahimkhani M, Khavari-Daneshvar H,Sharif R.Asymptomatic bacteriuria and Pyuria in pregnancy. ActaMedical Iranica.2008; 46: 409-412.

3. Loh K, Sivalingam N. Urinary tract infections in pregnancy. Malaysian Fam Physician.2007; 2:54-57.

4. Geatchew F, Gizachewy Y, Yitayih W, Zufan S. The prevalence and antimicrobial susceptibility pattern of bacterial uropathogen isolated from pregnant women. Euro. J. Exp. Bio, 2012,2(5):1497-1502.

5. Gunther N, Lockatell V, Jhonson D, Mobly T. In vivo dynamics of type 1 fimbria regulation in uropathogenic E. coli during experimental urinary tract infections. Infec. Immun. 2001; 69: 2838-46.

6. Sahm D, Thornsberry C, Mayfield D, Jones M, Karlowsky J. Multidrug resistance urinary tract isolates of E.coli: prevalence and patient demographicsin the united states in 2000. Antimicrob Agents Chemother. 2001; 45: 1402-06.

7. Sheffield J, Cunningham F. Urinary tract infection in women. Obstet Gynaecol, 2005; 106, 1085-1092

8. Lee M, Bozzo P, Einarson A, Koren G. Urinary tract infection in pregnancy. Can Fam Physician, 2008; 54, 853-854.

9. Wagenlehner F, Weidner W, Naber K. An update on uncomplicated urinary tract infections in women. Curr Opin Urol, 2009; 19:368-374.

10. Duarte G., Marcolin A, Quintana S, Cavalli R. Urinary tract infection in pregnancy. Rev Duarte G., Marcolin A, Quintana S, Cavalli R. Urinary tract infection in pregnancy. Rev Bras Gynecol Obstet, 2008; 30,93-100.

11. Jolley J, Wing D. Pyelonephritis in pregnancy: an update on treatment options for optimal outcomes. Drugs, 2010; 70: 1643-1655.

12. Gilstrap L, Cunningham F, Walley P. Acute pyelonephritis in pregnancy: an anterospective study. Obstet Gynaecol, 1981; 57, 409-413.

13. Hill J, Sheffield J, McIntire D, Wendel G., Acute pyelonephritis in pregnancy. Obstet Gynaecol, 2005; 105:18-23

14. Alemu A, Moges F, Shiferaw Y, Tafess K, Kassu A, Anagaw B, Agegn A. Bacterial profile and drug susceptibility pattern of urinary tract infection in pregnant women at University of Gondar Teaching Hospital, Northwest Ethiopia. BMC research notes 2012, 5:197.

15. Assefa A, Asrat D, Woldreamanuel Y, G/Hiwot Y, Abdella A, Melesse T: Bacterial profileand drug susceptibility pattern of urinary tract infection in pregnant women at Tikur Anbessa Specialized Hospital Addis Ababa, Ethiopia. Ethiop Med J 2008, 46: 227 235. 